\title{
Antiplatelet and anticoagulant therapy in elderly people with type 2 diabetes mellitus in Poland (based on the PolSenior Study)
}

\author{
Beata Łabuz-Roszak ${ }^{1}$, Agnieszka Machowska-Majchrzak², Michał Skrzypek ${ }^{3}$, \\ Małgorzata Mossakowska ${ }^{4}$, Jerzy Chudek ${ }^{5}$, Andrzej Więcek ${ }^{6}$, Maciej Wawrzyńczyk², \\ Beata Łącka-Gaździk ${ }^{7}$, Krystyna Pierzchała²
}

\author{
${ }^{1}$ Department of Basic Medical Sciences, Faculty of Public Health, Medical University \\ of Silesia, Katowice, Poland \\ ${ }^{2}$ Department of Neurology in Zabrze, Medical University of Silesia, Katowice, Poland \\ ${ }^{3}$ Department of Biostatistics, Faculty of Public Health, Medical University of Silesia, \\ Katowice, Poland \\ ${ }^{4}$ International Institute of Molecular and Cell Biology, Warsaw, Poland \\ ${ }^{5}$ Department of Pathophysiology, Medical Faculty in Katowice, Medical University \\ of Silesia, Katowice, Poland \\ ${ }^{6}$ Department of Nephrology, Transplantation and Internal Medicine, Medical \\ University of Silesia, Katowice, Poland \\ ${ }^{7}$ Department of Nephrology, Diabetology and Internal Diseases, Medical University \\ of Silesia, Katowice, Poland
}

Submitted: 3 September 2015

Accepted: 30 November 2015

Arch Med Sci 2017; 13, 5: 1018-1024

DOI: https://doi.org/10.5114/aoms.2017.68948

Copyright (c) 2017 Termedia \& Banach

\section{Abstract}

Introduction: Type 2 diabetes mellitus (T2DM) is an important and common cardiovascular risk factor. The purpose of the study was to evaluate the frequency of use of oral antiplatelet drugs (OAPs) and oral anticoagulant drugs (OACs) among the elderly with T2DM in Poland.

Material and methods: The study was based on the data collected in the Polish national PolSenior study.

Results: Among 4979 PolSenior participants aged 65 and over, 883 (17.8\%) had previously diagnosed T2DM. Among them, 441 (49.9\%) used at least one drug in pharmacological cardiovascular prevention, i.e. OAPs (mostly ASA) in $405(45.9 \%)$ cases and OACs in 38 (4.3\%). The use of these drugs significantly depended on the sex $(p=0.02)$ and personal income $(p=0.05)$. Age, place of residence and level of education did not affect the prevalence of pharmacological prevention. Previous stroke and myocardial infarction were mostly associated with OAPs, whereas a history of atrial fibrillation (AF) was related to OAC treatment. Among participants treated with OAPs, therapy was applied as secondary cardiovascular prevention in $211(52.1 \%)$ subjects, and as primary prevention in 194 (47.9\%) subjects. Among participants treated with OACs, 24 (64.9\%) persons had a history of AF. Secondary cardiovascular pharmacological prevention should be considered in 45 untreated participants $(12.5 \%)$, and primary cardiovascular pharmacological prevention (SCORE $\geq 10$ and/or AF) in 154 participants (42.7\%).

Conclusions: Cardiovascular pharmacological prevention in the elderly with T2DM in Poland seems to be unsatisfactory. Educational programmes concerning current recommendations for pharmacological cardiovascular prevention should be developed among general practitioners.

Key words: diabetes mellitus, elderly, anticoagulant drugs, antiplatelet drugs.

\section{Corresponding author:}

Beata Łabuz-Roszak MD, PhD Department of Basic

Medical Sciences

Faculty of Public Health

Medical University

of Silesia

18 Piekarska St

41-902 Bytom, Poland

Phone: +48 605097110

E-mail: broszak@sum.edu.pl 


\section{Introduction}

Type 2 diabetes mellitus (T2DM) is an important and common cardiovascular risk factor. Cerebrovascular events occur 2-4 times more frequently in individuals with T2DM as compared to persons of the same age and sex without disorders of carbohydrate metabolism. Coronary artery disease is the primary cause of death in diabetic patients aged > 65 years (about 70\%), whereas cerebrovascular disease is the primary cause of death in about $15 \%[1,2]$. The most frequent causes of thrombotic events in T2DM are the following: impaired platelet function (increased processes of adhesion, aggregation, and activation, increased platelet turnover), endothelial dysfunction (increased expression of adhesion molecules, enhanced production of vasoconstrictors such as angiotensin II, endothelin 1, thromboxane etc., decreased production of vasodilators such as nitric oxide, increased oxidative stress) and impaired fibrinolysis [3-5]. Until 2010, the use of acetylsalicylic acid (ASA) for cardiovascular protection had been recommended to each diabetic patient. Recent randomized clinical trials and meta-analyses found no statistically significant reduction in the risk of major cardiovascular events when ASA was compared with placebo in individuals with T2DM and no overt cardiovascular disease [6-9]. Currently, the recommendations for cardiovascular prevention and the use of ASA in diabetic patients are similar to the recommendations for individuals without T2DM. Following the current European guidelines (2012), ASA is recommended in all patients with overt cardiovascular disease [10]. In both asymptomatic subjects and in diabetic patients, ASA could be considered when the risk of death due to cardiovascular disease is high (5-10\% or higher in the next 10 years).

Little is known about pharmacological cardiovascular prevention in the elderly with T2DM in Poland. Therefore, the purpose of the study was to evaluate the frequency of use of oral antiplatelet drugs (OAPs) and oral anticoagulant drugs (OACs) among the elderly in Poland with T2DM and the association of the frequency with clinical characteristics and concomitant cardiovascular risk factors.

\section{Material and methods}

The study was based on the data collected in the Polish national PolSenior study, a research project commissioned by the Polish Ministry of Science and Higher Education, known as "Medical, psychological, sociological and economic aspects of aging of people in Poland (PolSenior)" (PBZMEiN-9/2/2006). A detailed description of the project had been previously published $[11,12]$. The project, approved by the Bioethics Commission of the Medical University of Silesia in Katowice, was conducted from October 2008 to April 2012.

The study group included participants from the PolSenior project aged 65 years and over who affirmatively answered the question: "Have you ever been diagnosed with diabetes?" and who were being treated with hypoglycaemic drugs. The following data obtained from the PolSenior database were used and analysed: age, sex, place of residence (village or city, or stay at a nursing home), level of education, personal income, a history of other cardiovascular risk factors (coronary heart disease, previous myocardial infarction, congestive heart failure, pharmacologically treated hypertension, a history of AF, previous stroke, pharmacologically treated dyslipidemia, active smoking) and body mass index (BMI). The frequency of the drug use was based on the data collected in the medical part of the questionnaire, including international and trade names of drugs taken by participants.

The study was approved by the Bioethics Commission of the Medical University of Silesia in Katowice, Poland.

\section{Statistical analysis}

Statistical data analysis was performed using SAS version 9.2 (SAS Institute Inc., Gary, NC). The level of statistical significance was $p<0.05$. To evaluate the statistical significance of between-group differences for qualitative data, the $\chi^{2}$ test and Fisher's exact test were used, whereas Student's $t$-test and the Wilcoxon rank sum test were used for quantitative data (for normally and non-normally distributed data, respectively). The normal distribution assumption was checked by means of the Shapiro-Wilk test. A model of logistic regression was used to analyse the association between cardiovascular risk factors and treatment with OAPs and/or OACs.

The 10-year risk of fatal cardiovascular disease (Systematic Coronary Risk Evaluation [SCORE]) was calculated using the following data: sex (male/female), age (years), systolic blood pressure $(\mathrm{mm} \mathrm{Hg})$, total cholesterol $(\mathrm{mmol} / \mathrm{l})$ and history of current smoking [13].

\section{Results}

Among all the PolSenior participants aged 65 and over ( $n=4979), 4242(82.5 \%)$ subjects answered the question: "Have you ever been diagnosed with diabetes?" Among them, 883 (17.8\%) subjects were being pharmacologically treated due to T2DM (with insulin and/or an oral hypoglycaemic drug) and they constituted the study group.

The study group consisted of 484 (54.8\%) women and 399 (45.2\%) men. The mean age of 
Table I. The frequency of use of OAPs and OACs in the study group $(N=883)$

\begin{tabular}{|lcc|}
\hline Variable & $\begin{array}{c}\text { International } \\
\text { drug name }\end{array}$ & $\begin{array}{c}\text { Number of respon- } \\
\text { dents using the drug } \\
n(\%)\end{array}$ \\
\hline $\begin{array}{l}\text { OAP } \\
(n=405)\end{array}$ & Acetylsalicylic acid & $391(44.3)$ \\
\cline { 2 - 3 } & Clopidogrel & $19(2.2)$ \\
\cline { 2 - 3 } $\begin{array}{l}\text { OAC } \\
(n=38)\end{array}$ & Acenocoumarol & $15(1.7)$ \\
\cline { 2 - 3 } & Warfarin & $37(4.2)$ \\
\hline
\end{tabular}

$O A P$ - oral antiplatelet drugs, $O A C$ - oral anticoagulant drugs.

the examined subjects was $78.6 \pm 8.3$ years, similar for both sexes ( $78.7 \pm 8.6$ vs. $78.5 \pm 8.1$ years, respectively, $p=0.92$ ).

Among all the examined subjects treated for diabetes, 441 (49.9\%) subjects used at least one drug in pharmacological prevention of cardiovascular diseases. The OAPs were regularly used by 405 (45.9\%) subjects, OACs by 38 (4.3\%) subjects. Three hundred and eighty-one (43.1\%) T2DM participants used one OAP, 24 (2.7\%) used two different OAPs, 36 (4.3\%) one OAC, and 2 subjects ( $0.2 \%)$ used two OACs. Additionally, 2 (0.2\%) persons simultaneously used an OAP and an OAC (Table I).

The sex of the participants was associated with the prevalence of pharmacological cardiovascular prevention. The percentage of diabetic women using OAPs and/or OACs (46.3\%; $n=224)$ was lower than the corresponding percentage of diabetic men $(54.4 \% ; n=217)(p=0.02)$. The mean age
(79.0 \pm 8.1 years) of participants taking OAPs and/ or OACs was similar to the mean age $(78.2 \pm 8.5$ years) of participants not treated with these drugs $(p=0.10)$.

The majority of the examined T2DM subjects lived in cities $(66.1 \% ; n=584)$. No difference was observed in pharmacological cardiovascular prevention between urban $(n=284 ; 48.6 \%)$ and rural residents ( $n=157 ; 52.5 \%)(p=0.28)$. Additionally, no significant differences were found between different regions of Poland (data not shown).

The frequency of use of OAPs and/or OACs was not associated with the level of education (Table II). Personal income had a significant effect on the frequency of use of OACs only $(p=0.05)$, not OAPs (Table III).

The frequency of cardiovascular risk factors in the whole study group is shown in Table IV. The association between the use of OAP and/or OAC drugs and the presence or the absence of cardiovascular risk factors is presented in Table $\mathrm{V}$. Among all of the cardiovascular risk factors, previous stroke and previous myocardial infarction were most strongly associated with OAP treatment, and a history of AF was associated with OAC treatment (Table VI).

Subsequently, we performed an analysis of probable indications for antiplatelet therapy in the examined subjects with T2DM. Among all of the participants treated with OAPs $(n=405)$, this therapy was applied as secondary cardiovascular prevention in 211 (52.1\%) participants. However, 194 (47.9\%) subjects used OAPs in primary pre-

Table II. Pharmacological cardiovascular prevention and education ( $n=848$, ND in 35 examined subjects)

\begin{tabular}{|c|c|c|c|c|}
\hline Level of education & $N$ & $\begin{array}{c}\text { OAP and/or OAC } \\
n(\%)\end{array}$ & $\begin{array}{l}\text { OAP } \\
n(\%)\end{array}$ & $\begin{array}{l}\mathrm{OAC} \\
n(\%)\end{array}$ \\
\hline Incomplete elementary & 99 & $49(49.5)$ & $46(46.5)$ & $3(3.0)$ \\
\hline Complete elementary & 381 & $192(50.4)$ & $177(46.5)$ & $15(3.9)$ \\
\hline Vocational & 96 & $49(51.0)$ & $45(46.9)$ & $5(5.2)$ \\
\hline Secondary & 205 & $104(50.7)$ & $94(45.9)$ & $10(4.9)$ \\
\hline University & 67 & $34(50.8)$ & $30(44.8)$ & $4(6.0)$ \\
\hline$P$-value & & 0.99 & 0.99 & 0.86 \\
\hline
\end{tabular}

$O A P$ - oral antiplatelet drugs, $O A C$ - oral anticoagulant drugs, ND - not documented.

Table III. Association between personal income and use of OAPs and OACs ( $n=702$, ND in 181)

\begin{tabular}{|c|c|c|c|c|}
\hline $\begin{array}{l}\text { Personal income } \\
\text { [PLN/month] }\end{array}$ & $N$ & $\begin{array}{c}\text { OAP and/or OAC } \\
n(\%)\end{array}$ & $\begin{array}{l}\text { OAP } \\
n(\%)\end{array}$ & $\begin{array}{l}\text { OAC } \\
n(\%)\end{array}$ \\
\hline$\leq 1000$ & 271 & $134(49.5)$ & $122(45.0)$ & $12(4.4)$ \\
\hline $1001-1500$ & 264 & $128(48.5)$ & $113(42.8)$ & $16(6.1)$ \\
\hline $1501-2000$ & 98 & $49(50.0)$ & $48(49.0)$ & $1(1.0)$ \\
\hline 2001 and more & 69 & $40(58.0)$ & $33(47.8)$ & $7(10.1)$ \\
\hline$P$-value & & 0.57 & 0.71 & 0.05 \\
\hline
\end{tabular}


Table IV. Frequency of cardiovascular risk factors in the study group $(N=883)$

\begin{tabular}{|lcc|}
\hline Risk factor & $\boldsymbol{N}(\%)$ & ND $(n)$ \\
\hline Previous stroke & $92(10.5)$ & 6 \\
\hline Pharmacologically treated hypertension & $701(79.4)$ & - \\
\hline Previous myocardial infarction & $142(16.8)$ & 66 \\
\hline History of atrial fibrillation & $203(24.9)$ & 35 \\
\hline Coronary heart disease (without myocardial infarction) & $166(19.6)$ & 37 \\
\hline Congestive heart failure & $134(15.8)$ & - \\
\hline Pharmacologically treated dyslipidaemia & $341(38.6)$ & 6 \\
\hline Current smoking & $60(6.8)$ & 63 \\
\hline Overweight/obesity $\left(\mathrm{BMI} \geq 25 \mathrm{~kg} / \mathrm{m}^{2}\right)$ & $708(86.3)$ & \\
\hline
\end{tabular}

Table V. Frequency of use of OAP and/or OAC in association with presence (+) or absence (-) of cardiovascular risk factors

\begin{tabular}{|c|c|c|c|c|}
\hline Risk factor & & $\begin{array}{c}\text { OAP and/or OAC } \\
n(\%)\end{array}$ & $\begin{array}{l}\text { OAP } \\
n(\%)\end{array}$ & $\begin{array}{l}\text { OAC } \\
n(\%)\end{array}$ \\
\hline \multirow[t]{3}{*}{ Previous stroke } & $(+)$ & $65(70.7)$ & $61(66.3)$ & $4(4.4)$ \\
\hline & $(-)$ & $373(47.5)$ & $341(43.4)$ & $34(4.3)$ \\
\hline & $P$-value & $<0.01$ & $<0.01$ & 0.21 \\
\hline \multirow{3}{*}{$\begin{array}{l}\text { Pharmacologically } \\
\text { treated hypertension }\end{array}$} & $(+)$ & $386(55.1)$ & $352(50.2)$ & $36(5.1)$ \\
\hline & $(-)$ & $55(30.2)$ & $53(29.1)$ & $2(1.1)$ \\
\hline & $P$-value & $<0.01$ & $<0.01$ & 0.02 \\
\hline \multirow{3}{*}{$\begin{array}{l}\text { Previous myocardial } \\
\text { infarction }\end{array}$} & $(+)$ & $106(74.7)$ & $100(70.4)$ & $6(4.2)$ \\
\hline & $(-)$ & $310(44.0)$ & $283(40.2)$ & $29(4.1)$ \\
\hline & $P$-value & $<0.01$ & $<0.01$ & 0.95 \\
\hline \multirow{3}{*}{$\begin{array}{l}\text { History of atrial } \\
\text { fibrillation }\end{array}$} & $(+)$ & $118(58.1)$ & $94(46.3)$ & $24(11.8)$ \\
\hline & $(-)$ & $286(46.6)$ & $275(44.8)$ & $13(2.1)$ \\
\hline & $P$-value & $<0.01$ & 0.71 & $<0.01$ \\
\hline \multirow{3}{*}{$\begin{array}{l}\text { Coronary heart } \\
\text { disease (without } \\
\text { myocardial infarction) }\end{array}$} & $(+)$ & $116(69.9)$ & $102(61.5)$ & $16(9.6)$ \\
\hline & $(-)$ & $301(44.1)$ & $282(41.4)$ & $19(2.8)$ \\
\hline & $P$-value & $<0.01$ & $<0.01$ & $<0.01$ \\
\hline \multirow{3}{*}{$\begin{array}{l}\text { Congestive heart } \\
\text { failure }\end{array}$} & $(+)$ & $94(70.2)$ & $83(61.9)$ & $12(9.0)$ \\
\hline & $(-)$ & $323(45.4)$ & $302(42.4)$ & $22(3.1)$ \\
\hline & $P$-value & $<0.01$ & $<0.01$ & $<0.01$ \\
\hline \multirow{3}{*}{$\begin{array}{l}\text { Pharmacologically } \\
\text { treated dyslipidaemia }\end{array}$} & $(+)$ & $212(62.2)$ & $195(57.2)$ & $19(5.6)$ \\
\hline & $(-)$ & $229(42.3)$ & $210(38.8)$ & $19(3.5)$ \\
\hline & $P$-value & $<0.01$ & $<0.01$ & 0.14 \\
\hline \multirow[t]{3}{*}{ Current smoking } & $(+)$ & $24(40.0)$ & $22(36.7)$ & $2(3.3)$ \\
\hline & $(-)$ & $416(50.9)$ & $382(46.8)$ & $36(4.4)$ \\
\hline & $P$-value & 0.10 & 0.13 & 0.69 \\
\hline \multirow{3}{*}{$\begin{array}{l}\text { Overweight/obesity } \\
\left(\mathrm{BMI} \geq 25 \mathrm{~kg} / \mathrm{m}^{2}\right)\end{array}$} & $(+)$ & $355(50.1)$ & $324(45.8)$ & $33(4.7)$ \\
\hline & $(-)$ & $58(51.8)$ & $54(48.2)$ & $4(3.6)$ \\
\hline & $P$-value & 0.76 & 0.63 & 0.61 \\
\hline \multirow[t]{3}{*}{ Gender } & $\mathrm{F}$ & $224(46.3)$ & $206(42.6)$ & 19 (3.9) \\
\hline & $M$ & $217(54.4)$ & $199(49.9)$ & $19(4.8)$ \\
\hline & $P$-value & 0.02 & 0.03 & 0.54 \\
\hline
\end{tabular}

Data presented as $n$ (\%). OAP - oral antiplatelet drugs, OAC - oral anticoagulant drugs, (+) - risk factor present, (-) - risk factor absent, $F$-female, $M$ - male. 
Table VI. Association of cardiovascular risk factors with OAP and/or OAC treatment. Data are presented as OR $(95 \% \mathrm{CI})$ and $p$-value

\begin{tabular}{|c|c|c|c|c|c|c|}
\hline \multirow[t]{2}{*}{ Risk factor } & \multicolumn{2}{|c|}{ OAP and/or OAC } & \multicolumn{2}{|l|}{ OAP } & \multicolumn{2}{|l|}{ OAC } \\
\hline & OR $(95 \% \mathrm{Cl})$ & $P$-value & OR $(95 \% \mathrm{Cl})$ & $P$-value & OR $(95 \% \mathrm{Cl})$ & $P$-value \\
\hline Previous stroke & $3.28(1.77-6.07)$ & $<0.01$ & $2.79(1.57-4.97)$ & $<0.01$ & $1.37(0.45-4.21)$ & 0.58 \\
\hline $\begin{array}{l}\text { Pharmacologically treated } \\
\text { hypertension }\end{array}$ & $2.55(1.67-3.90)$ & $<0.01$ & $2.27(1.48-3.46)$ & $<0.01$ & $\begin{array}{c}3.28(0.74- \\
14.48)\end{array}$ & 0.12 \\
\hline $\begin{array}{l}\text { Previous myocardial } \\
\text { infarction }\end{array}$ & $2.50(1.53-4.09)$ & $<0.01$ & $2.50(1.57-3.99)$ & $<0.01$ & $0.62(0.23-1.66)$ & 0.34 \\
\hline History of atrial fibrillation & $1.12(0.75-1.67)$ & 0.59 & $0.76(0.51-1.14)$ & 0.19 & $4.24(1.91-9.42)$ & $<0.01$ \\
\hline $\begin{array}{l}\text { Coronary heart disease } \\
\text { (without myocardial } \\
\text { infarction) }\end{array}$ & $2.11(1.32-3.37)$ & $<0.01$ & $1.81(1.15-2.84)$ & 0.01 & $2.04(0.85-4.88)$ & 0.11 \\
\hline Congestive heart failure & $1.38(0.84-2.28)$ & 0.21 & $1.28(0.79-2.07)$ & 0.32 & $1.24(0.49-3.12)$ & 0.65 \\
\hline $\begin{array}{l}\text { Pharmacologically treated } \\
\text { dyslipidaemia }\end{array}$ & $1.54(1.10-2.17)$ & 0.01 & $1.51(1.08-2.11)$ & 0.02 & $1.21(0.56-2.62)$ & 0.63 \\
\hline Current smoking & $0.67(0.36-1.26)$ & 0.21 & $0.67(0.36-1.26)$ & 0.21 & $0.91(0.19-4.23)$ & 0.90 \\
\hline $\begin{array}{l}\text { Overweight/obesity } \\
\left(\mathrm{BMI} \geq 25 \mathrm{~kg} / \mathrm{m}^{2}\right)\end{array}$ & $0.75(0.46-1.23)$ & 0.25 & $0.77(0.47-1.25)$ & 0.29 & $0.91(0.3-2.78)$ & 0.86 \\
\hline Sex (male/female) & $1.53(1.10-2.12)$ & 0.01 & $1.38(1.00-1.91)$ & 0.05 & $1.85(0.87-3.95)$ & 0.11 \\
\hline
\end{tabular}

$O A P$ - oral antiplatelet drugs, $O A C$ - oral anticoagulant drugs.

vention of cardiovascular disease. Among them, $24(15.0 \%)$ participants had no indications (SCORE $<5 \%), 57$ (35.6\%) participants had relative indications (SCORE $\geq 5 \%$ and $<10 \%)$, and $79(49.4 \%)$ participants had definitive indications (SCORE $\geq 10 \%$ and/or atrial fibrillation (AF)). It was impossible to establish indications in 34 (17.5\%) participants (missing data).

Among all the participants treated with OACs ( $n=38), 24(64.9 \%)$ subjects had a history of AF. Other indications for anticoagulant therapy could not be established due to the lack of necessary data.

An analysis of optional indications for preventive therapy among participants not treated with OAPs or OACs $(n=442)$ was also performed. It was not possible to establish them in 81 (18.3\%) participants (missing data). In the group of subjects with determined optional indications, only $26(7.2 \%)$ subjects had no indications for such therapy (SCORE < 5\%), and 136 (37.7\%) participants had relative indications (SCORE $\geq 5 \%$ and $<10 \%)$. Secondary cardiovascular pharmacological prevention should be considered in 45 (12.5\%) participants, and primary cardiovascular pharmacological prevention (SCORE $\geq 10 \%$ and/or AF) in $154(42.7 \%)$ participants.

\section{Discussion}

About two million people are diagnosed with T2DM in Poland, and this number is still growing, which is associated with the process of aging of the population (the peak of incidence occurs after the age of 65). In the examined group of more than four thousand elderly subjects in Poland, about a quarter were being pharmacologically treated for T2DM

Cardiovascular disease is the leading cause of morbidity and mortality in persons with T2DM. Also, the aging process is related to cardiovascular mortality.

Antihypertensive therapy, lowering cholesterol levels with statins, proper glycaemic control and lifestyle modification (regular physical activity, smoking cessation) reduce the risk of cardiovascular complications [10]. Antithrombotic therapy is recommended in all people, including diabetics with an overt cardiovascular disease. According to the Antiplatelet Trialists' Collaboration meta-analysis, treatment with antiplatelet drugs (mostly ASA) causes a $25 \%$ reduction in the risk of a cardiovascular event [14].

The percentage of the elderly with T2DM treated with OAPs and/or OACs was higher than the percentage of the general PolSenior population receiving pharmacological preventive therapy (49.9\% vs. $35.9 \%$ - data from our previously published paper) [15]. This might be associated with the indications for ASA therapy in diabetic people that were present when the current study was being conducted (all diabetics were recommended to use ASA, including in primary cardiovascular prevention) as well as with a higher incidence of other cardiovascular risk factors (hypertension, dyslipidaemia, previous myocardial infarction, previous stroke, etc.) in diabetic subjects as compared with the general PolSenior study group.

Similarly to previous studies, ASA was the drug most commonly used by subjects with T2DM in 
cardiovascular prevention [16-20], which was confirmed by $44.3 \%$ of the examined participants, fewer than in former Polish studies concerning a similar population [19]. In the study of Opolski et al. in a group of older ( $>55$ years) subjects with T2DM $(n=210)$, the prevalence of ASA use was $53 \%$ [21]. This difference was even much more significant knowing that subjects in the study of Opolski et al. had no overt cardiovascular disease.

Our study revealed that concomitant cardiovascular risk factors such as previous stroke, hypertension, previous myocardial infarction, AF, coronary artery disease, congestive heart failure, and dyslipidaemia were significantly associated with a higher frequency of pharmacological cardiovascular therapy. Past stroke and myocardial infarction were mostly associated with OAP therapy. These drugs were taken by a similar number of people with previous stroke $(66.3 \%)$ and with previous myocardial infarction (70.4\%), which is comparable to other study results [15-19].

On the other hand, we found that some risk factors such as smoking, obesity or overweight were not associated with a higher frequency of antithrombotic therapy. The percentage of respondents with T2DM and obesity or overweight was high in the present study, i.e. almost $90 \%$. However, only $50 \%$ were treated with OAPs and/or OACs. On the other hand, Lucha-López et al. described a sample of 38 Spanish T2DM subjects with overweight and obesity, and ASA was used by $87 \%$ of participants [22].

Generally, more than half of examined T2DM individuals had overt cardiovascular disease and used OAPs as secondary prevention. Only $15 \%$ of subjects using OAPs as primary prevention had no indications (SCORE < 5\%), and more than 30\% had relative indications (SCORE $\geq 5 \%$ and $<10 \%$ ). Further prospective studies would be needed to establish the prevalence of cardiovascular events and/or side effects (especially haemorrhage) in them.

The use of OAPs and/or OACs significantly depended on the sex and personal income, which was similar to the general Polsenior population [15]. Contrary to our previous study, age, place of residence and level of education did not affect the prevalence of pharmacological prevention in subjects with diabetes [15].

Our study reveals that cardiovascular pharmacological prevention in the elderly with T2DM seems to be unsatisfactory. The analysis of optional indications for OAP and/or OAC therapy showed that secondary cardiovascular pharmacological prevention should be considered in more than $12 \%$ of participants not using it, and primary cardiovascular pharmacological prevention (SCORE $\geq 10 \%$ and/or atrial fibrillation) in almost $50 \%$ of subjects. Unfortunately, due to the lack of data, contraindications for antithrombotic therapy could not be established.

In conclusion, cardiovascular pharmacological prevention in the elderly with T2DM seems to be unsatisfactory. Educational programmes should be developed among general practitioners and specialists. Such programmes should concern current recommendations for pharmacological cardiovascular prevention.

In some cases the missing data were an obstacle to estimating the indications for therapy with OAPs and/or OACs.

\section{Acknowledgments}

Implemented under publicly funded project No. PBZ-MEIN-9/2/2006, Ministry of Science and Higher Education, Poland.

\section{Conflict of interest}

The authors declare no conflict of interest.

\section{References}

1. Haffner SM, Lehto S, Rönnemaa T, Pyörälä K, Laakso M. Mortality from coronary heart disease in subjects with type 2 diabetes and in non diabetic subjects with and without prior myocardial infarction. N Eng J Med 1998; 339: 229-34.

2. Erem C, Kuzu UB, Deger O, Can G. Prevalence of gestational diabetes mellitus and associated risk factors in Turkish women: the Trabzon GDM Study. Arch Med Sci 2015; 11: 724-35.

3. Angiolillo DJ, Suryadevara S. Aspirin and clopidogrel: efficacy and resistance in diabetes mellitus. Best Pract Res Clin Endocrinol Metabol 2009; 23: 375-88.

4. Cerbone AM, Macarone-Palmieri N, Saldalamacchia G, Coppola A, Di Minno G, Rivellese AA. Diabetes, vascular complications and antiplatelet therapy: open problems. Acta Diabetol 2009; 46: 253-61.

5. Rao GH. Management of type-2 diabetes with antiplatelet therapies: special references to aspirin. Front Biosci 2011; 3: 1-15.

6. Pignone M, Alberts MJ, Colwell JA, et al. Aspirin for primary prevention of cardiovascular events in people with diabetes. JACC 2010; 55: 2878-86.

7. Belch J, MacCuish A, Campbell I, et al. The prevention of progression of arterial disease and diabetes \{POPADAD trial: factorial randomized placebo controlled trial of aspirin and antioxidants in patients with diabetes and asymptomatic peripheral arterial disease [abstract]. BMJ 2008; 337: 1840.

8. Ogawa H, Nakayama M, Morimoto T, et al. Low-dose aspirin for primary prevention of atherosclerotic events in patients with type 2 diabetes: a randomized controlled trial. JAMA 2008; 300: 2134-214.

9. Leung WY, So W, Steward D, et al. Lack of benefits for prevention of cardiovascular disease with aspirin therapy in type 2 diabetic patients - a longitudinal observational study. Cardiovasc Diabetol 2009; 8: 57-67.

10. Perk J, Backer G, Gohlke H, et al. The Fifth Joint Task Force of the European Society of Cardiology and Other Societies on Cardiovascular Disease Prevention in Clinical Practice (Constituted by representatives of nine so- 
cieties and by invited experts): European guidelines on cardiovascular disease prevention in clinical practice: executive summary (version 2012). Eur Heart J 2012; 33: 1635-701.

11. Bledowski P, Mossakowska M, Chudek J, et al. Medical, psychological and socioeconomic aspects of aging in Poland. Assumptions and objectives of the PolSenior project. Exp Gerontol 2011; 46: 1003-9.

12. Medical, psychological and socioeconomic aspects of aging in Poland. Monography of PolSenior Project [Polish]. Mossakowska M, Więcek A, Błędowski P (eds). Termedia, Poznan 2012.

13. Conroy RM, Pyorala K, Fitzgerald AP, et al.; the SCORE project group. Estimation of ten-year risk of fatal cardiovascular disease in Europe: the SCORE project. Eur Heart J 2003; 24: 987-1003.

14. Antithrombotic Trialist' Collaboration. Collaborative meta-analysis of randomized trials of antiplatelet therapy for prevention of death, myocardial infarction, and stroke in high risk patients. BMJ 2002; 324: 71-86.

15. Labuz-Roszak B, Pierzchala K, Skrzypek M, Swiech M, Machowska-Majchrzak A. Oral anticoagulant and antiplatelet drugs used in prevention of cardiovascular events in elderly people in Poland. BMC Cardiovascular Disorders 2012; 12: 98.

16. Asberg S, Henriksson KM, Farahmand B. Ischemic stroke and secondary prevention in clinical practice. Stroke 2010; 41: 1338-42.

17. Wei JW, Wang JG, Huang Y, et al.; the ChinaQUEST Investigators. Secondary prevention of ischaemic stroke in urban China. Stroke 2010; 41: 967-74.

18. Wachtel TM, Kucia AM, Greenhill JA. Secondary prevention for acute coronary syndrome in rural South Aus tralia: Are drugs best? What about the rest? Rural and Remote Health 2008; 8: 967 (Online) [http://www.rrh. org.au] Accessed 5 October 2014

19. Pignone M, Anderson GK, Binns K, Tilson HH, Weisman SM. Aspirin use among adults aged 40 and older in the United States: results of a national survey. Am J Prev Med 2007; 32: 403-7.

20. Sola D, Rossi L, Schianca GP, et al. Sulfonylureas and their use in clinical practice. Arch Med Sci 2015; 11: 840-8.

21. Opolski G, Strojek K, Kurzelewski M, Ostrowski M, Rabczenko D. Cardiovascular therapy, diagnostic procedures, and control of risk factors in patients with diabetes or coronary artery disease in Poland: the Kardia-Pol registry. Pol Arch Med Wewn 2012; 122: 413-21.

22. Lucha-López MO, Lucha-López AC, Vidal-Peracho C, et al. Analysis of a sample of type 2 diabetic patients with obesity or overweight and at cardiovascular risk: a cross sectional study in Spain. BMC Res Notes 2014; 7: 48. 